\title{
UM OLHAR SOBRE ASPECTOS VOLTADOS À INOVAÇÃO NAS INDÚSTRIAS DE MÉDIO PORTE NA REGIÃO DA AMAUC
}

A LOOK AT ASPECTS RETURNING TO INNOVATION IN MIDDLE EARTH INDUSTRIES IN THE

AMAUC REGION

ADRIANA TROCZINSKI STORTI ${ }^{1}$

EVANDRO CARLO PEDROZO ${ }^{2}$

\begin{abstract}
RESUMO: O tema inovação conduz atualmente a muitas reflexões acerca do seus conceitos e profundidade. Quando a avaliação sai do nível básico é comum perceber o questionamento das pessoas sobre o real significado e entendimento que tinham até então sobre inovação. Frequentemente confundido com o termo "invenção", a inovação é um trabalho construído por várias mãos e percorre um longo caminho até inserir-se na cultura de uma organização. Esta pesquisa objetivou realizar um levantamento nas indústrias de porte médio, que possuam entre 100 e 499 colaboradores, localizadas na região da AMAUC (Associação dos Municípios do Alto Uruguai Catarinense). Foi levando em conta a compreensão do tema sobre a ótica da direção, onde situou-se e relacionou-se suas vivências na inovação. Isso incluiu status de possíveis projetos atuais e/ou futuros, políticas de inovação e cultura organizacional aliada a um contexto de aplicabilidade. Para tanto, foram aplicados questionários semiestruturados aos dirigentes de todas as indústrias que compunham a amostra, em forma de entrevista, visando maior fidedignidade no entendimento das perguntas e coerência nas respostas.
\end{abstract}

Palavras-chave: Inovação. Indústrias. AMAUC.

ABSTRACT: The theme of driving current innovation and many reflections on its concepts and depth. When the evaluation comes out of the basic mind it is common to perceive people's questioning about the real meaning and understanding that there is until then about innovation. The term "invention" is often confused with innovation. It is a work built by many hands and it has to go a long way until to be part of an organization culture. The purpose of this research is to realize a collecting in a medium business, so, in the industries that have from 100 to 499 employees, located AMAUC region. It is necessary to understand the theme in relation to the perspective of direction, situate, and relate their experiences in innovation, including possible status of current projects and / or future political innovation and organizational culture combined with an applicability of context. Therefore, it was applied in semi-structured questionnaires to managers of all industries that compose up the sample as in an interview seeking greater reliability in understanding the questions and having meaning in the answers.

\footnotetext{
Data de submissão: 23/08/2016 Data de aceite: 19/02/2018 Data de publicação:

${ }^{1}$ Professora Curso de Administração. Mestre em Agronegócio - UFRGS. Doutora em Administração - UNISINOS

2 Especialista em Gestão de Pessoas
} 
Key-words: Innovation. Industries. AMAUC.

\section{INTRODUÇÃo}

Em tempos atuais, fatores como queda de vendas na indústria catarinense e nacional (8,9\% e 6,6\% respectivamente até agosto de 2015$)$, instabilidade econômica e desconfiança do mercado internacional $(12,7 \%$ de retração até julho de 2015$)$, acabam expondo as fragilidades enfrentadas pelo país, bem como a falta de competitividade em muitos setores (PORTAL DA INDÚSTRIA, 2015).

Briscoe (2008) avalia que o Brasil nas duas últimas décadas avançou em níveis internacionais em áreas como agricultura, aeronáutica e exploração de petróleo em águas profundas. Por ser uma nação grande e desigual, precisa melhorar a sua condição nos sistemas educacionais, de infraestrutura tecnológica e políticas de inovação. $\mathrm{O}$ autor destaca a capacidade do país em inovar, mas em escalas menores e incapazes de acompanhar o ritmo de inovador de outras nações (RODRIGUEZ; DAHLMAN; SALMI, 2008, p.25).

O tema inovação vem sendo alvo de constantes estudos e discussões como uma obviedade para o crescimento e a competitividade da indústria nacional. A despeito das linhas de incentivo disponíveis e a relevância que o assunto merece, constantemente surgem discussões acerca do real conhecimento do empresário brasileiro sobre o tema inovação.

A inclusão de dados regionais levantados pela Federação das Indústrias do Estado de Santa Catarina (FIESC), pelas unidades do SESI, do SENAI e do IEL, na região da AMAUC que abriga 15 municípios, 3 estima-se, ainda que de forma empírica e não sistematizada, a incipiência do envolvimento das indústrias da região em relação ao tema inovação.

Essa incipiência é corroborada pela FIESC em razão da baixa procura por cursos de capacitação, treinamentos, seminários, serviços de consultorias, gestão de pessoas, segurança no trabalho, investimentos em tecnologia, planejamento e desenvolvimento, bem como, demais fatores relacionados. Esses fatores são primordiais para a melhoria dos processos de inovação.

O objetivo da pesquisa foi compreender a visão do público dessas esferas frente à inovação, incluindo o conhecimento sobre a temática, as práticas, projetos e dificuldades enfrentadas. Optou-se pela escolha das empresas consideradas de médio porte, que possuem entre 100 e 499 colaboradores, por fazerem parte de um grupo de significância econômica e produtiva na região, e pela possibilidade de entrevistar $100 \%$ da população diretamente relacionada com o nível estratégico das instituições.

Com o resultado desta pesquisa, espera-se obter dados relevantes para auxiliar o industriário numa melhor compreensão do tema, entender quais os caminhos pretendidos

\footnotetext{
${ }^{3}$ A região da AMAUC abrange atualmente as cidades de Alto Bela Vista, Arabutã, Arvoredo, Concórdia, Itá, Ipumirim, Irani, Ipira, Jaborá, Lindóia Do Sul, Paial, Peritiba, Piratuba, Presidente Castelo Branco, Seara, Xavantina.
} 
pelas indústrias da região no quesito inovação, e ofertar suporte informativo sobre práticas atuais que promovam o incentivo industrial no processo da inovação. Além do industriário, outras entidades serão contempladas como secretarias municipais voltadas ao setor industrial, associações comerciais e industriais, agências de fomento, pesquisadores, estudantes em geral. Também serão contempladas instituições que de alguma forma trabalhem junto a esse público e careçam de dados regionais sobre o assunto.

\section{REFERENCIAL TEÓRICO}

Inovar, segundo Proença (2015, p. 41), é entendido como a principal estratégia para aumentar a competitividade das empresas, promover o desenvolvimento econômico e posicionar-se com em novos mercados de maneira sólida. Já o termo inovação o autor define como:

\footnotetext{
A implementação de um produto ou serviço novo ou significativamente melhorado, de um processo, de um novo método de marketing, de um novo método organizacional nas práticas de negócios, na organização do local de trabalho ou nas relações externas, ou ainda a reorganização de parte ou toda a instituição.
}

Serafim (2011, p. 23) comenta fatores que permeiam o tema relatando que no mundo corporativo as pessoas utilizam-se de fontes discutíveis para justificar que inovação, criatividade e invenção têm a mesma definição ainda que interligadas. $O$ autor contextualiza que a criatividade trata da capacidade humana em produzir ideias, respostas e soluções diante de um problema ou necessidade. A invenção é uma etapa do processo que torna a ideia tangível e implementa a criatividade. E, a inovação é o resultado da introdução de algum elemento com certa novidade capaz de criar valor econômico. Inovação no meio empresarial é o objetivo final, conclui.

Segundo Araújo et al apud Bruland \& Moery (2015, p.11) a inovação deu o seu impulso inicial desde a revolução industrial quando foram entendidas como fatores relevantes para a competitividade e, a partir de então, tomando força nas revoluções industriais seguintes, não somente como força motriz para as nações, mas dentro do contexto organizacional, educacional, científico e tecnológico.

Desde então, estudos foram surgindo e correlacionando a inovação, mas foi Schumpeter (CROSSAN E APAYDIN, 2010, p.1155) quem apresentou o tema como questão central para o entendimento do crescimento econômico e, a partir deste momento, tornouse um ícone no assunto sendo seguido por muitos e criticado por tantos outros.

No Brasil, a inovação ainda possui $60 \%$ de prioridade estratégica acima da média global, mas nos desdobramentos dos números, quando essa prioridade é gerencial ou operacional, ela cai para cerca de $40 \%$, confirmando que a inovação não ultrapassa a barreira da alta direção (TADEU, 2014, p.2).

Em um levantamento de âmbito nacional acerca do tema inovação industrial, em 2005 mostrou-se que dentre as empresas brasileiras, somente $2 \%$ se destacam como inovadoras e diferenciadoras de produtos. Esse montante corresponde a $26 \%$ do faturamento industrial brasileiro, emprega mais de $13 \%$ da força de trabalho industrial e tem produtividade de $37 \%$ superior às demais. Pode-se acrescer a esses dados que o salário médio nessas empresas é superior em mais que $100 \%$, e os colaboradores permanecem 
nessas empresas $36 \%$ a mais do que em outras empresas nacionais especializadas em produtos nacionais sem diferenciação (PROENÇA, 2015, p.41).

São necessárias cerca de 60 ideias no funil da gestão da inovação para que se concretize uma inovação incremental, enquanto para produzir uma inovação radical ou revolucionária são necessárias mais de 3000 ideias, completa o autor.

Entende-se por inovação incremental quando esta modifica, aperfeiçoa, melhora, simplifica, consolida processos e serviços de produção, e distribuição já em atividade. Enquanto que a inovação radical consiste em introduzir novos produtos ou serviços de maneira que estes proporcionem novos negócios ou expandam-se em novas indústrias, ou ainda, que possam causar mudanças significativas na empresa de maneira a gerarem novos valores de mercado (INNOSUPPORT, 2015, P.12).

As organizações bem-sucedidas que combinam mudança em tecnologia e mudança no modelo de negócio podem criar inovação. Davila, Epstein e Shelton (2007, p.50) complementam que além disso para integrar com sucesso um sólido modelo de inovação à mentalidade empresarial, o CEO e sua equipe de liderança devem equilibrar tanto os elementos de negócio quanto os de inovação tecnológica.

Para Roger e Schoemaker (1971) a inovação é uma ideia, uma prática ou um objeto percebido como novo pelo indivíduo, e é complementada pela visão de Freeman (1982) que apontou que a inovação industrial incluiu técnica, design, fabricação, gerenciamento e atividades comerciais pertinentes ao marketing de um produto novo (ou incrementado), ou do primeiro uso comercial de um processo, ou equipamento novo (ou incrementado).

Esta abordagem é apontada por Rothwell e Gardiner (1985) que também enfatiza que a inovação não implica, necessariamente, apenas na comercialização de grandes avanços tecnológicos (inovação radical), mas também inclui a utilização de mudanças de know-how tecnológico em pequena escala (melhoria ou inovação por incremento). A inovação como um processo, que envolve geração, adoção, implementação e incorporação de novas ideias é apontada por Van de Vem et al. (1989).

Uma relação da inovação com o alcance da vantagem competitiva, com a aplicação de novas tecnologias e novas formas de fazer algo é abordada por Porter (1990), que logo mais tarde, é discutida pela abordagem econômica como um processo de aplicação de uma ideia nova para criar um produto ou processo novo (GALBRAITH, 1997).

Destaca-se, ainda, a importante contribuição no avanço dos conceitos sobre inovação dado em 2005 pela OCDE - Organização para a Cooperação e Desenvolvimento Econômico. No Manual de Oslo, aponta-se a inovação como a implementação de um produto (bem ou serviço) novo ou significativamente melhorado, ou um processo, ou um novo método de marketing, ou um novo método organizacional nas práticas de negócios, na organização do local de trabalho, ou nas relações externas. Desta forma, entende-se que o conceito ganha maior amplitude em definições mais recentes, também abordadas por Prahalad (2005), como adoção de novas tecnologias que permitem aumentar a competitividade das organizações.

No entanto para que uma empresa seja realmente inovadora é primordial que a conduta do seu representante líder seja de pura inovação, que esteja no cerne da sua cultura e por consequência na cultura organizacional. Essa estratégia tem de ser top down (tem de partir da direção executiva para os demais cargos no organograma). A inovação deve ser estabelecida como prioridade para a obtenção sistêmica do apoio do restante da equipe (SERAFIN, 2011, p. 89). 
Rocha (2009, p. 99) complementa o assunto citando outros elementos tidos como essenciais para o processo de inovação: liderança, estratégia, processos, recursos, indicadores de desempenho e incentivos.

Proença (2015) chama a atenção para um processo importante no surgimento de novos produtos, na promoção e alteração de dados nomeados de destruição criativa. Para o autor é necessário que sejam sucateados processos de produção no decorrer do tempo em detrimento do surgimento de espaços novos e, como consequência, hábitos novos. Esse impulso mantém o movimento da dinâmica capitalista obrigando a empresa a movimentarse em busca de sobrevivência e, nessa busca, surgem os novos bens de consumo, novos métodos de produção, novos métodos de consumo, novas tecnologias e novas formas de organização industrial.

Eis que chega-se num ponto chave quando o assunto é inovação. O que é considerado inovação e os tipos ideais na busca por uma melhor competitividade com um desempenho eficiente. Num estudo conduzido por Araújo, Silva e Brandão (2015, p.12) a inovação possui as seguintes classificações:

Inovação de produto - Entendido como os processos de descoberta, experimentação, desenvolvimento, imitação e adoção de novos produtos em um dado contexto (Dosi, 1988).

Inovação de processo - trata-se da implementação ou introdução de um método de produção ou distribuição novo ou melhorado significativamente (Manual de Oslo, 2005, p.58).

Inovação de mercado - Significa criar novos mercados a partir de condições já vigentes (Bessant e Tide, 2009).

Inovações comportamentais - Pode ser entendido com a substituição de paradigmas culturais capazes de promover o uso de determinados artefatos sob nova ótica.

Inovação estratégica - Segundo o manual de Oslo é aquela que a organização utiliza para competir no mercado, independentemente do tipo de posicionamento.

Já Proença (2015, p. 41) fala em quatro tipos de inovação oriundos do manual de Oslo (FINEP, 2005, p.57), e um quinto, de acordo com seu entendimento. São eles:

Inovação de produto - Introdução de bem ou serviço novo ou significativamente melhorado no que concerne as suas características ou uso previstos.

Inovação de processo - Implementação de um método de produção, ou distribuição novo, ou significativamente melhorado.

Inovação de marketing - É a implementação de um novo método de marketing envolvendo mudanças significativas na concepção do produto ou embalagem no posicionamento de produto em sua promoção ou fixação de preços.

Inovação organizacional - É a implementação de um novo método organizacional nas práticas de negócios da empresa, na organização do seu local de trabalho ou em suas relações externas.

Inovação institucional - É a implementação de uma nova visão, de uma nova missão, de novas diretrizes, de uma nova política, ou ainda de um marco regulador que impacte no comportamento econômico independente do seu âmbito.

Antes da estratégia de qual caminho inovador a empresa trilhará, convém avaliar como a cultura da empresa perceberá tais mudanças, e como isso será digerido no decorrer dos projetos que serão implantados.

Ross (apud MALDANER, 2006 p.69) aponta que a decisão de inovar dentro ou fora da empresa depende de alguns elementos centrais para sustentar tal inovação: 
- Um modelo mental de comprometimentos compartilhado;

- A disponibilidade de verba para investimento inicial;

- Estruturas que encorajem a experimentação e tolerem o fracasso;

- Capacidade de mensurar o valor das inovações.

Como complemento, Ross enfatiza que várias empresas estão preferindo desenvolver sua cultura com o objetivo de valorizar e aproveitar ideias surgidas na organização.

Sobre um dos principais fatores envolvidos no embrião da inovação, a CNI e o SEBRAE (2015, p.13) pressupõem que para empreender e inovar é necessário enfrentar riscos de diferentes naturezas como: risco tecnológico, sobre as incertezas inerentes à pesquisa e aos quesitos tecnológicos; risco comercial, no que se refere às dificuldades de um produto novo; riscos regulatórios, que dependem de órgãos governamentais e/ou regulares; e ainda, riscos referentes a fontes de fomento e financiamento.

Os modelos de gestão devem ser modificados para absorver a inovação e protegê-la tanto das obsolescências internas como das mudanças no ambiente competitivo. Uma organização inovadora e competitiva disposta a quebrar paradigmas e obter os resultados esperados, depende da sua cadeira de valores, e da sua capacidade de adaptação para gerar valor ao cliente (ROCHA, 2009 p.13).

Para Rocha (2009, pg. 31) a empresa que quiser implementar inovação deve fazer um recrutamento criativo que encoraje a livre expressão das ideias dos colaboradores e recompensá-los por isso, estimulando pensamentos novos, a ação, a desordem a desobediência provocando a "destruição criativa".

Essa mudança de paradigma envolve custos e investimentos que surgem como um dos principais empecilhos do empresário que, às vezes, não está disposto a arcar com esta responsabilidade sozinho. Por isso, com o passar do tempo foram surgindo alternativas de fomento para a inovação. O primeiro modelo de financiamento para a inovação descrito na literatura ocorreu por volta de 1950 quando foi criado o Conselho Nacional de Desenvolvimento Científico e Tecnológico (CNPq) e a Coordenação de Aperfeiçoamento de Pessoal e Ensino Superior (CAPES) que se ocupavam das ações relacionadas com ciência e tecnologia (PROENÇA et al, 2015, p. 29).

$\mathrm{Na}$ década de 90 teve o marco legal brasileiro da inovação. Mais precisamente em 1993 com a lei $n 8.661$ de incentivos fiscais para a capacitação tecnológica da indústria e da agropecuária (alterada em 1997 pela lei 9.532). Posteriormente surgiu a lei da informática nascida das leis 8.248 e 8.387 , alterada depois por diversas outras leis, decretos e fundos. A partir de então, foram sendo criadas outras leis, decretos e fundos que se propunham a incentivar a ciência e tecnologia (C\&T), pesquisa e desenvolvimento (P\&D), e áreas correlatas da inovação. Em 2 de dezembro de 2004 foi regulamentada a lei 10.973 (que foi alterada em dezembro de 2010 pela lei 12.349) conhecida como a lei da inovação federal, que serviu de base para várias outras leis estaduais da inovação. Em 21 de novembro de 2005 entra em vigor o capítulo III da lei 11.196 conhecida como a Lei Do Bem (GRIZENDI, 2011, pg. 15).

Segundo o Manual de Incentivos à Inovação da C.E.S.A.R (2009, p.07), atualmente o Brasil pode incentivar a inovação dando vida a políticas públicas através de duas linhas estratégicas: 
- Definição de uma política de desenvolvimento produtivo (PDP) proposta na esfera federal que fundamenta ações do governo estimulando o mercado nacional através da inovação;

- Proposição de um arcabouço jurídico envolvendo leis que preveem investimento de recursos públicos para pesquisa, desenvolvimento e inovação e inventivos para a isenção de impostos governamentais.

Dentre as principais políticas de incentivo em vigor há a Lei da Informática, Lei da Inovação, Lei do Bem, Lei Rouanet da Pesquisa, Subvenção Econômica, Empréstimos FINEP, FUNTEC BNDES e parcerias com centros de PD\&l no Brasil que podem servir como incentivadores na busca pela inovação.

\section{METODOLOGIA}

Nesse trabalho a metodologia se deu através da abordagem dedutiva que, segundo Marconi e Lakatos (2010, p.74), tem como objetivo explicar o conteúdo das premissas e de natureza exploratória. Conforme Selltiz et al apud Oliveira (2011, p.20) são aqueles estudos que buscam descobrir ideias e intuições, na tentativa de adquirir maior familiaridade com o fenômeno pesquisado. Quanto à compilação de dados, foi utilizado o modelo quanti-quali.

Realizou-se um levantamento de dados com base em $100 \%$ da população que são as 14 indústrias de médio porte (entre 100 e 499 colaboradores entre todas as unidades no momento da pesquisa) situadas na região da AMAUC em Santa Catarina. Estas informações foram estratificadas da base de dados da Federação das Indústrias do Estado de Santa Catarina (2015) e da Federação Catarinense de Municípios (FECAN, 2015).

Foram realizadas entrevistas guiadas por questionários semiestruturados aplicados diretamente com o proprietário ou diretor geral das indústrias selecionadas.

Esses dirigentes participaram de uma entrevista pessoal com o pesquisador, realizada com apoio de um questionário com 31 questões voltadas à inovação e atividades consideradas pré-requisitos para que essa prática fosse possível, como treinamento de pessoal, cultura organizacional, planejamento orçamentário, infraestrutura, parcerias, entre outras questões. Quanto ao instrumento de coleta de dados utilizado para esta pesquisa, optou-se pela entrevista pessoal, com auxílio de um questionário semiestruturado desenvolvido pelos autores. Este questionário foi construído considerando a teoria sobre inovação e um estudo ainda não publicado de Fonseca (2015), que esboça alguns questionamentos sobre a temática de inovação em empresas, e que abrigam as seguintes categorias analíticas: capacitação e processos de inovação.

Sobre as perguntas, quatro foram descritivas e as demais foram de múltipla escolha. Para o ajuste do score nas questões que exigiam avaliação de níveis, foi utilizada a escala Likert de cinco pontos sendo 01 para menos atende e 05 para mais atende. Com o objetivo de diminuir as possíveis interferências e garantir um tempo mínimo de 30 minutos para as respostas. Foram agendadas previamente todas as entrevistas desconsiderando outros respondentes que não fossem os diretores. Antes de aplicar o questionário foi realizada uma breve explanação sobre as considerações da literatura acerca do tema "inovação" e o que a bibliografia tecnicamente considera "inovador". Procurou-se, desta forma, algum alinhamento sobre o objetivo da pesquisa e o entendimento do entrevistado sobre o tema, 
bem como esclarecer possíveis dúvidas sobre a escolha. A aplicação foi presencial para garantir a fidedignidade ao questionário e o entendimento pleno das questões, o que foi corroborado no decorrer das aplicações. O Google formulários foi a ferramenta utilizada para registro das informações e obtenção de scores e gráficos.

\section{RESULTADOS E DISCUSSÕES}

\subsection{PANORAMA GERAL}

Do total dos dirigentes entrevistados na amostra, 92,9 \% deles estão na empresa há mais de 10 anos, sendo que a maior fatia 35,7\% concentra-se na faixa entre 11 a 20 anos. Mais da metade desse grupo $57,1 \%$ atuam nesta função há mais de uma década configurando um gestor que conhece bem a empresa e sua equipe. Levando em conta que do total de empresas $71,4 \%$ possuem no máximo três sócios, desenha-se um cenário que, em tese, facilita o diálogo para decisões mais densas.

Com relação à quantidade de colaboradores nas indústrias, surge um perfil bem característico de que $76,9 \%$ da amostra possui no máximo 200 colaboradores. A alegação é de que esse número atende a demanda e em alguns casos houve automação dos processos o que acabou por substituir uma parte da mão de obra não impactando em produção e receita.

Buscou-se, também, identificar a relação custo benefício da automação dentro da indústria, tratando esta abordagem como avanços em processos produtivos modernizados. Algumas indústrias apontaram que além de tratar-se de uma necessidade, ao mesmo tempo preenche um gargalo deixado pela falta de mão de obra e pela falta de comprometimento, já que alguns setores necessitam de produção em alta escala para manter a empresa bem alinhada às demandas do mercado e atenta às premissas da competitividade.

\subsection{SOBRE O INVESTIMENTO EM CAPACITAÇÃO}

A pesquisa também procurou compreender se as indústrias em estudo designaram investimentos em capacitação, visto ser importante que o pessoal de diferentes níveis hierárquicos avancem em termos de conhecimento e possam acompanhar e contribuir o com novos processos inovativos. Neste sentido, quando questionados sobre esta categoria, as indústrias entrevistadas dizem possuir política de investimento para capacitação e desenvolvimento de pessoal. As respostas demonstraram certo equilíbrio indicando que este processo existe nas empresas, mas com pouca sistematização, pois apenas 7,1\% sentiram-se confortáveis em situar a empresa no maior nível (Gráfico 01). 


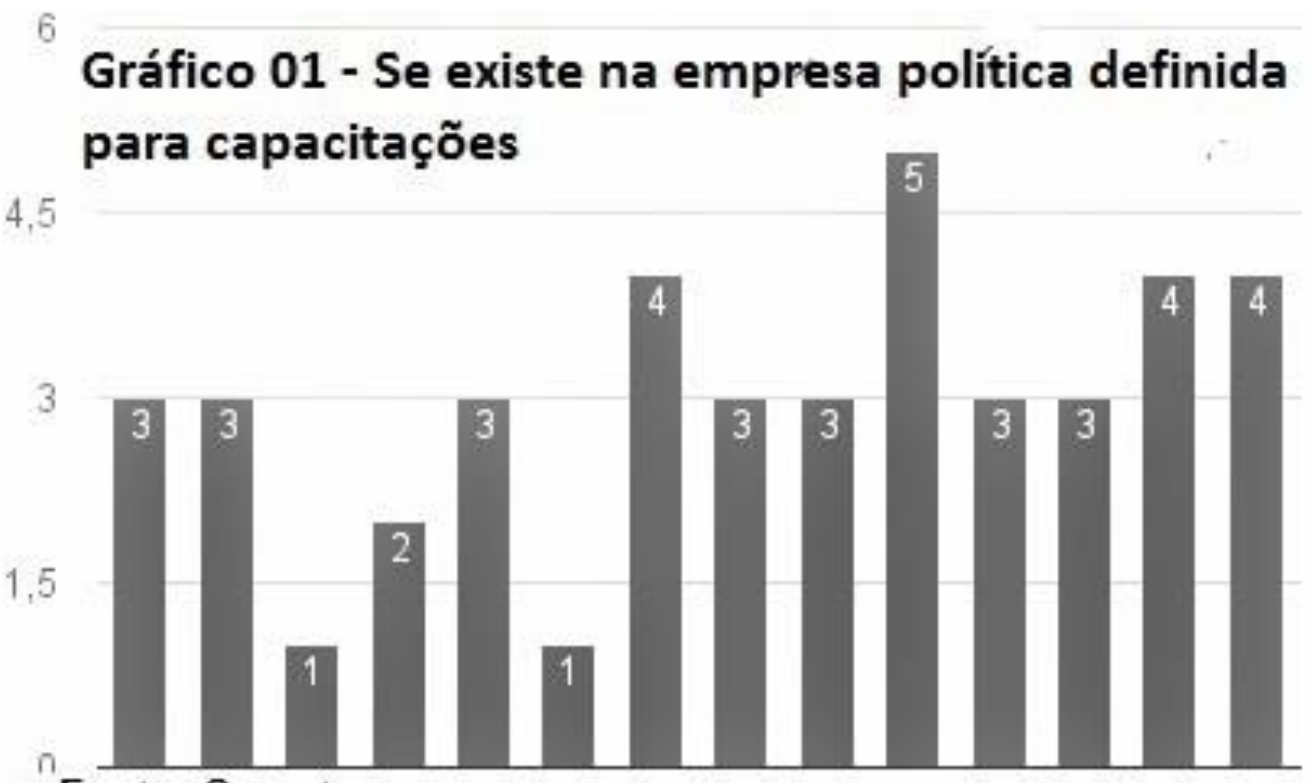

Fonte: Os autores

Com relação aos valores que os dirigentes estão dispostos a investir em treinamentos e mesmo todos informando realizarem tais investimentos, o maior volume $(35,7 \%)$ situou-se no nível inicial que compreende até $R \$ 10.000,00 / a n o$, o que daria pouco mais de $R \$ 800,00$ ao mês, valor considerado baixo para empresas desse porte. Mas, de maneira geral, houve um equilíbrio nesse quesito conforme é apresentado no Gráfico 02. Nota-se que todas investem, mesmo que com clara disparidade, uma vez que a população está na mesma categoria e em níveis econômicos semelhantes.

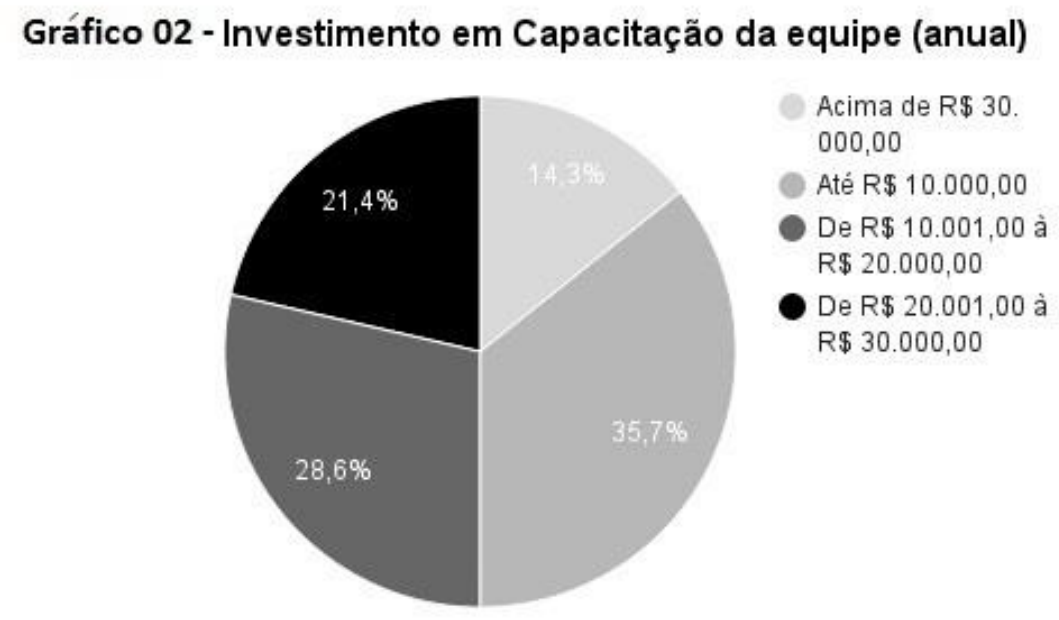

Fonte: Os autores 
Tabela 01

\begin{tabular}{|c|c|c|c|c|c|}
\hline & \multicolumn{5}{|c|}{$\leftarrow$ MENOS ATENDE - MAIS ATENDE $\rightarrow$} \\
\hline & 1 & 2 & 3 & 4 & 5 \\
\hline $\begin{array}{l}\text { Os processos de estímulo à inovação e a novas } \\
\text { ideias estão disseminados entre todos os níveis da } \\
\text { empresa de maneira que os colaboradores sintam- } \\
\text { se incentivados a participar? }\end{array}$ & $14,3 \%$ & $35,7 \%$ & $14,3 \%$ & $28,3 \%$ & $7,1 \%$ \\
\hline $\begin{array}{l}\text { A liderança da empresa tem consciência de que o } \\
\text { processo de inovação possui riscos e mesmo } \\
\text { assim está disposta a incentivá-lo? }\end{array}$ & $14,3 \%$ & $14,3 \%$ & $21,4 \%$ & $21,4 \%$ & $28,6 \%$ \\
\hline $\begin{array}{l}\text { Existe na empresa uma estrutura que armazena } \\
\text { dados sobre o negócio, possibilitando o } \\
\text { compartilhamento desse conhecimento entre os } \\
\text { colaboradores envolvidos? }\end{array}$ & $28,6 \%$ & $21,4 \%$ & $14,3 \%$ & $21,4 \%$ & $14,3 \%$ \\
\hline $\begin{array}{l}\text { A empresa é vista pelo mercado com uma fonte de } \\
\text { informação junto aos seus pares dentro do seu } \\
\text { setor de atuação? }\end{array}$ & $14,3 \%$ & $7,1 \%$ & $0 \%$ & $57,1 \%$ & $21,4 \%$ \\
\hline $\begin{array}{l}\text { A empresa está localizada ou conectada a um polo } \\
\text { ou região que propicie ações de inovação? }\end{array}$ & $14,3 \%$ & $35,7 \%$ & $21,4 \%$ & $21,4 \%$ & $7,1 \%$ \\
\hline $\begin{array}{l}\text { A empresa utiliza-se de mecanismos de } \\
\text { comunicação via internet (redes sociais, sites, } \\
\text { blogs, SAC/Chat, etc.) com o intuito de aproximar } \\
\text { o seu produto do desejo deste cliente? }\end{array}$ & $14,3 \%$ & $21,4 \%$ & $21,4 \%$ & $42,9 \%$ & $0 \%$ \\
\hline $\begin{array}{l}\text { A empresa registra, acompanha, avalia e audita } \\
\text { regularmente (com indicadores específicos) os } \\
\text { projetos de inovação em andamento? }\end{array}$ & $64,3 \%$ & $7,1 \%$ & $14,3 \%$ & $14,3 \%$ & $0 \%$ \\
\hline $\begin{array}{l}\text { A proporção de investimentos anual em inovação } \\
\text { (novos produtos, processos, atividades de P\&D) } \\
\text { em relação ao orçamento geral é adequada para a } \\
\text { promoção de inovação na empresa? }\end{array}$ & $50,0 \%$ & $14,3 \%$ & $14,3 \%$ & $14,3 \%$ & $7,1 \%$ \\
\hline $\begin{array}{c}\text { Existem projetos de inovação a iniciar dentro dos } \\
\text { próximos } 5 \text { anos que esteja definido no planejamento } \\
\text { da empresa? }\end{array}$ & $21,4 \%$ & $21,4 \%$ & $7,1 \%$ & $28,6 \%$ & $7,1 \%$ \\
\hline $\begin{array}{l}\text { A empresa tem infraestrutura adequada para } \\
\text { atividades de } P \& D \& I \text { além das necessidades normais do } \\
\text { seu funcionamento? }\end{array}$ & $57,1 \%$ & $21,4 \%$ & $14,3 \%$ & $7,1 \%$ & $0 \%$ \\
\hline $\begin{array}{l}\text { Posicione-se quanto à importância da inovação frente } \\
\text { ao seu negócio dentro do setor industrial? }\end{array}$ & $0 \%$ & $7,1 \%$ & $21,4 \%$ & $14,3 \%$ & $57,1 \%$ \\
\hline $\begin{array}{l}\text { Atualmente a empresa considera-se preparada para a } \\
\text { inovação incluindo planejamento e politicas internas, } \\
\text { equipe tecnicamente qualificada (teórico/prático) sobre } \\
\text { o tema e cultura organizacional alinhada com premissas } \\
\text { inovadoras? }\end{array}$ & $21,4 \%$ & $21,4 \%$ & $50,0 \%$ & $7,1 \%$ & $0 \%$ \\
\hline $\begin{array}{c}\text { Sobre a relação da empresa, vínculos ou contratos com } \\
\text { institutos de pesquisas e universidades, opine } \\
\text { conforme escala. }\end{array}$ & $28,6 \%$ & $35,7 \%$ & $7,1 \%$ & $14,3 \%$ & $14,3 \%$ \\
\hline $\begin{array}{l}\text { A empresa conhece e avalia periodicamente todas as } \\
\text { possibilidades de acesso ao dinheiro público e privado } \\
\text { para subsidiar projetos de inovação? }\end{array}$ & $50,0 \%$ & $35,7 \%$ & $0 \%$ & $7,1 \%$ & $7,1 \%$ \\
\hline $\begin{array}{c}\text { A empresa tem infraestrutura e pessoal para o } \\
\text { desenvolvimento de tecnologias centrais para o seu } \\
\text { negócio? }\end{array}$ & $50,0 \%$ & $7,1 \%$ & $28,6 \%$ & $14,3 \%$ & $0 \%$ \\
\hline $\begin{array}{l}\text { A empresa identifica regularmente tecnologias } \\
\text { relevantes para o seu negócio (publicações, feiras, } \\
\text { congressos) e acompanha a sua evolução para gerar } \\
\text { inovações nos seus produtos e serviços? }\end{array}$ & $7,1 \%$ & $0 \%$ & $28,6 \%$ & $42,9 \%$ & $21,4 \%$ \\
\hline $\begin{array}{l}\text { A empresa busca parcerias com fornecedores para o } \\
\text { desenvolvimento/adaptação de tecnologias das quais } \\
\text { ainda não dispõem em seus processos, produtos e } \\
\text { serviços? }\end{array}$ & $28,6 \%$ & $7,1 \%$ & $14,3 \%$ & $28,6 \%$ & $21,4 \%$ \\
\hline
\end{tabular}

Fonte: Os autores

No processo de inovação, outro fator relevante para essa construção, foca-se na cultura organizacional. No que tange a esse assunto houve questionamento se os processos de estímulo à inovação estão disseminados na empresa de maneira que todos os colaboradores sintam-se incentivados a participar. Houve certo equilíbrio na balança das 
opiniões (conforme tabela acima) sugerindo que existe alguma cultura sobre o assunto nas empresas da região, mas não de maneira sólida.

Com relação aos riscos envolvidos no processo da inovação a indústria alega estar disposta a incentivá-los e assumi-los, mas relata não possuir uma estrutura para armazenar tais dados e posterior compartilhamento com a equipe.

A localização é algo que pode influenciar os planos de inovação, principalmente se o polo de atuação estiver distante, por isso essa resposta pode variar conforme o setor de atuação. A maioria dos entrevistados avalia que a localização na região da AMAUC não favorece e pode atrapalhar um pouco os processos de inovação. A distância dos polos produtivos de suas áreas foi o fator mais citado. Nesse quesito estão envolvidos os treinamentos técnicos, gargalos logísticos e assistência técnica como dificuldades por estarem somente em grandes capitais. A despeito da localização, a grande maioria considera que suas empresas são fontes de informação na região e constantemente são consultados por outros empresários sobre questões acerca do seu negócio. A maioria relata que contribui para a proximidade com o seu cliente nos diversos mecanismos da internet como canais específicos no site institucional, facebook, twitter e plataformas e-commerce.

Sobre os projetos inovadores, $64,3 \%$ afirmaram não possuir no momento nenhum projeto inovador no momento, $50 \%$ informaram que não há nada previsto para os próximos cinco anos, enquanto somente $7,1 \%$ informam possuírem algum projeto na gaveta. Sobre a política de investimento à inovação, 69,2\% afirmam não possuírem tal política. Mas quando questionados sobre a importância da inovação para o seu negócio no setor industrial, 57,1\% foram unânimes em corroborar tal importância.

Quando a pergunta foi se a proporção anual de investimentos à inovação é adequada frente ao orçamento geral, $50 \%$ foram enfáticos em dizer que não, mas questionados sobre os valores envolvidos, $42,9 \%$ não fez investimento algum nos últimos dois anos, enquanto $35,7 \%$ investiram mais de $\mathrm{R} \$ 80.000,00$.

Voltando ao viés técnico (tabela 01), a maioria não acompanha e/ou audita com registros e índices específicos os seus projetos tidos com inovadores em andamento e também não possui infraestrutura adequada para P\&D\&I (pesquisa, desenvolvimento e inovação), além das necessidades normais para o funcionamento.

Sobre vínculos com institutos de pesquisa ou universidades, que poderiam ser braços da empresa quando esta não está preparada para bancar investimento em infraestrutura própria, $64,3 \%$ votaram nos dois índices menores, informando que a empresa não possui tal relação e em alguns casos informando que não acham tão relevante essa parceria. No contraponto a grande maioria, $63,3 \%$ somado os dois índices mais altos, alegam estarem informados sobre as tecnologias mais relevantes para o seu negócio e atentos à evolução destes processos. Muitas dessas informações se dão em razão de parceiras com fornecedores, assim como vários dos treinamentos também são fornecidos por parceiros das indústrias como fabricantes de máquinas, fornecedores de matérias prima e profissionais ligados à FIESC (Federação das indústrias do Estado de Santa Catarina) como SESI, SENAI e IEL. 
Questionados se procuram parcerias com os fornecedores para o desenvolvimento/adaptação de tecnologias das quais ainda não possuem, obteve-se respostas diversas divididas e, por vezes incongruentes, pois enquanto uma parte alega achar interessante, a outra parte não possui o menor interessa nesse tipo de parceria.

Quanto à preparação para a inovação incluindo planejamento, política interna, equipe técnica especializada e cultura organizacional, a maioria demonstrou falta de consenso nessa área com poucas ações em atividade. Pesa nesse quesito as principais barreiras enfrentadas pela empresa no que se refere a projetos inovadores, onde a grande maioria $(35,7 \%)$ apontou dificuldades com recursos financeiros, enquanto $28,5 \%$ queixaramse dos custos envolvidos.

A ausência do tema na cultura organizacional foi respondida por $14,2 \%$ e outros $28,5 \%$ da falta de equipe capacitada para gerir a inovação. Ainda foram citados: falta de fabricante de máquinas inovadoras, a demora do mercado para absorver a inovação, posicionamento geográfico, incertezas, falta de estrutura, mercado instável, riscos envolvidos e dificuldades na homologação de processos inovadores.

Das empresas entrevistadas, a metade não conhece ou não avalia periodicamente as possibilidades de acesso ao dinheiro público e/ou privado para subsidiar projetos de inovação. Somado os dois índices que menos atendem essa questão haverá $75,7 \%$ dos diretores que praticamente desconhecem essas possibilidades e apenas uma empresa informou conhecer e acompanhar tais recursos.

\subsection{OUTROS IMPORTANTES DADOS DA PESQUISA}

Um dado que chama a atenção na pesquisa é o baixo número de indústrias de médio porte (entre 100 e 499 colaboradores) na região, sendo somente 14 de um total de 1357 indústrias (FIESC, 2015). Estratificando um pouco mais, percebe-se que destas, a grande maioria (dez) possui no máximo 200 colaboradores, e apenas uma possui mais de 400 colaboradores. Pode-se levantar hipóteses da razão deste panorama que vão desde a potencialidade da região a outros fatores relacionados ao negócio como mão de obra, questões econômicas, limitações de mercado, logística ou simplesmente pela cultura organizacional.

Algo relevante a se constatar sobre a população da amostra é que a grande maioria dos dirigentes entrevistados das indústrias da pesquisa possui uma administração familiar com poucos sócios. Isso pode ser um grande trunfo ou o inverso será absolutamente proporcional. Mas, como essas empresas estão há muitos anos nessas atividades possuem a autonomia necessária para implantar o sistema de trabalho que melhor lhes convêm.

Essas informações remetem automaticamente a duas questões muito importantes para qualquer empresa em qualquer mercado: a possível melhoria em aspectos competitivos e a capacitação.

A competitividade pode ser definida, de forma geral, como a capacidade de um sistema - país, setor industrial, grupo de empresas ou uma empresa específica - de 
atuar com sucesso em um dado contexto de negócios. Segundo, o desempenho competitivo de um sistema é condicionado por três conjuntos de fatores: fatores sistêmicos (externos ao ambiente da empresa), fatores estruturais (refere-se ao setor que a empresa opera e aos fatores que são parcialmente influenciados por ela) e fatores internos (relacionados aos traços e condições que estão à mercê dos empresários e executivos), Coutinho e Ferraz (2007, p.70 apud WOOD JR e CALDAS 2002).

O ranking da escola de negócios IMD foundation board (World Competitiveness Yearbook) é utilizado para medir a competitividade de um país no que diz respeito à inovação tecnológica, e em 2012, o Brasil caiu para $46^{\circ}$ atrás de países como, Hong Kong, China, Chile, Peru, entre outros. Este índice vem declinando nos últimos anos. (BRASIL, 2015)

Outro resultado que confirma tal condição foi divulgado pelo Fórum Econômico Mundial do mesmo ano baseado em uma lista com 144 países no qual credita o Brasil em $44^{\circ}$ (BRASIL, 2012).

Santa Catarina ocupa a 3a posição no estado e os números são um pouco mais animadores. Sustentam um score de 77,08 numa de escala de 0 a 100, mas cresce num ritmo bem mais lento que outros países mais desenvolvidos como Suíça, Cingapura e Suécia (G1.GLOBO.COM, 2015).

A inovação, em muitas vezes, contribui para o avanço da competitividade. Necessita ainda de uma cultura organizacional e apoio mínimo para ganhar espaço na empresa. Segundo Rocha (2009, p.35) o desenvolvimento de estratégias e elaboração de processos de inovação por si só são insuficientes para incutir a mentalidade da inovação na cultura da empresa de maneira que instigue as pessoas a intensificar a inovação sem bloqueios organizacionais. A pesquisa mostrou que metade da sua população tem consciência clara que os incentivos a novas ideias não estão disseminados em todos os setores da empresa, e nesse caso, talvez uma grande ideia que poderia auxiliar em algum processo jamais chegue à direção. Alguns responderam que essa possibilidade existe de maneira evidente, mas sem uma sistematização específica.

No que se refere a políticas de incentivo à inovação surgem os riscos e as respostas a esta questão foram algumas das mais inconstantes, pois embora metade da população tenha se posicionado como "incentivadores do risco", não ficou muito evidente nas respostas até onde a empresa estaria disposta a assumir esse risco e por quanto tempo, sendo possível entender que há a tolerância, mas não há uma mensuração e correlação entre riscos $x$ novas ideias.

A capacitação, como outro fator avaliado, surge na pesquisa como algo que tem importância clara e com boa valorização nas indústrias entrevistadas. São citados investimentos na graduação e pós-graduação do colaborador, capacitações em outros estados e inclusive capacitações internacionais. No entanto, na maioria dos casos, sem qualquer tipo de planejamento ou sistematização. A empresa investe, paga, amplia e tem consciência da necessidade, mas na grande maioria não registra ou prevê nos orçamentos.

O valor foi outro fator que surpreendeu, pois os maiores índices que surgiram na pesquisa investem aproximadamente $R \$ 800,00$ ao mês e em muitas vezes a capacitação se dá por parceiros que a fornecem gratuitamente.

Recentemente numa pesquisa realizada pela Associação Brasileira de Treinamento e Desenvolvimento (Portal ABTD, 2015) com 193 empresas de porte grande, constatou-se que o valor médio anual investido por colaborador nesse perfil de empresa era de $\mathrm{R} \$ 4.781,00$, ou seja, $86 \%$ da remuneração média mensal do colaborador da empresa. Embora essas 
empresas tenham mais condições e receitas maiores, o investimento em capacitações é proporcional ao seu tamanho.

Em empresas com premissas inovadoras, o colaborador além de ser capacitado com frequência, toma ciência de muitos dos processos dos negócios da empresa de maneira a utilizar estrategicamente aquela informação para lhe dar ganho competitivo nas suas atribuições, embora isso envolva algum desapego e novamente, riscos, que a empresa tem que assumir. Novamente houve equilíbrio nas respostas com pendência para o não compartilhamento das informações. Algumas alegações foram relacionadas à sistemática ainda inexistente desse fluxo, em outros caso, a empresa não considera essa premissa tão relevante ao negócio.

Quanto à comunicação via internet, sites, blogs, redes sociais diversas, chats, a grande maioria respondeu que não utiliza as principais ferramentas, mas percebe-se que varia muito de cada empresa, pois algumas utilizam ferramentas acima da média e a outra parte não utiliza um mínimo, resultando num equilíbrio geral médio. Do ponto de vista prático apenas exalta a disparidade nos processos de gestão à inovação nas indústrias entrevistadas.

Algumas respostas ganham entonação extra por serem centrais na pesquisa como, por exemplo, 69,2\% das indústrias entrevistadas não possuem política de investimento à inovação. Outras $64,30 \%$ não possuem nenhum projeto inovador no momento. $50 \%$ destas não têm previsão de nenhum projeto inovador nos próximos cinco anos o que indica apenas manutenção do mesmo negócio com os mesmo processos (Gráficos 03 e 04).

Gráfico 3 - Projetos de inovação para os próximos 5 anos

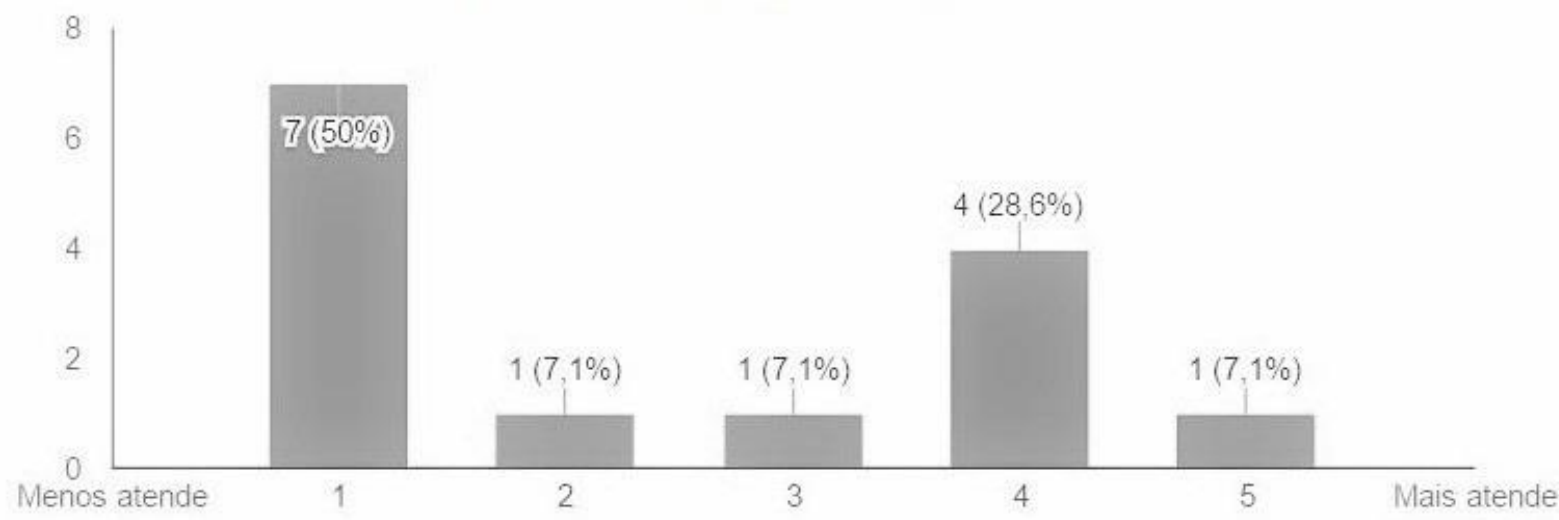

Fonte: Os autores 


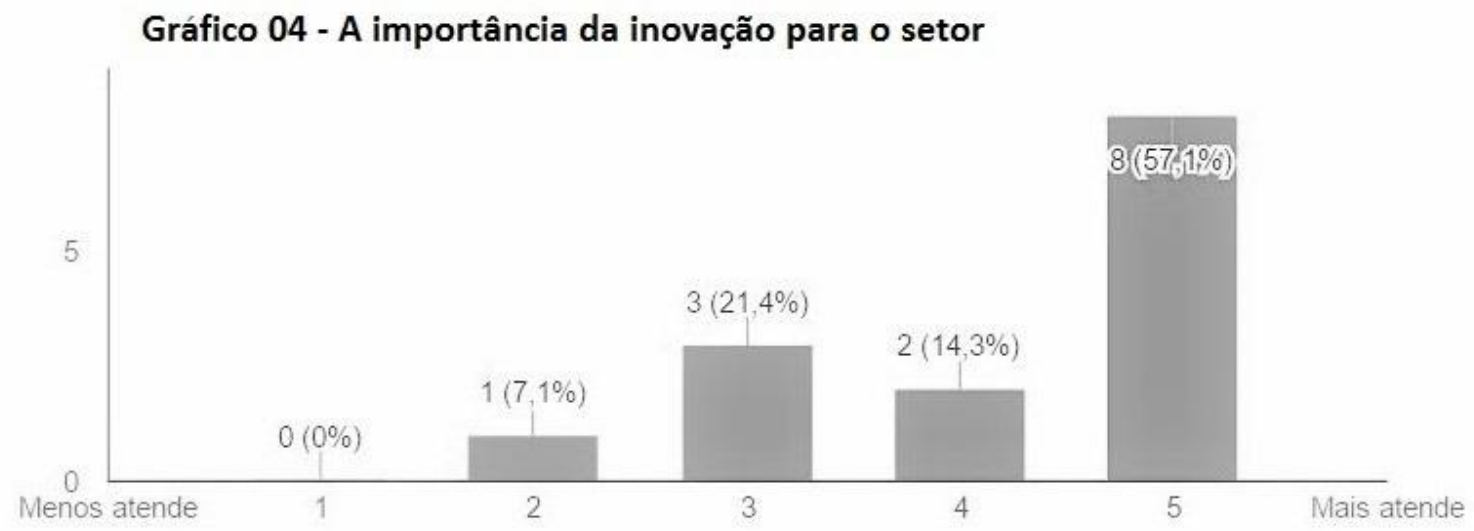

Fonte: Os autores

Quem não inova, não investe valor algum (seis indústrias), mas quem inova alto (cinco indústrias) investe valores bianuais superiores a $\mathrm{R} \$ 80.000,00$ e equilibram o grupo. Alguns desses falaram em milhões nesse período comprovando perfis bastante diferentes das indústrias da região no quesito inovação (Gráfico 05).

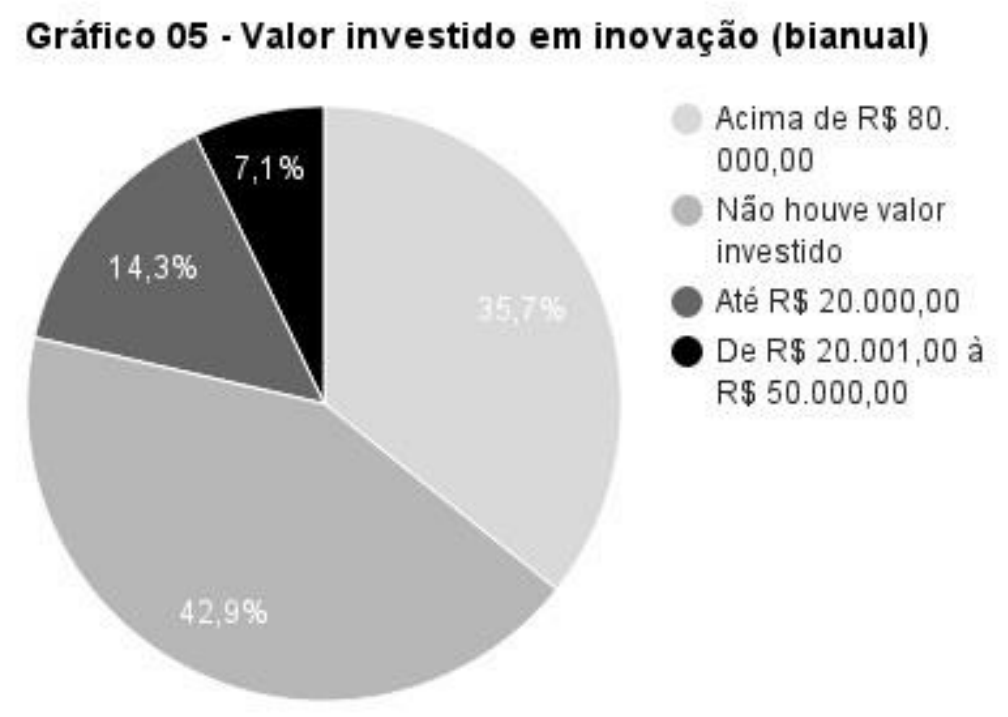

Fonte: Os autores

Ao mesmo tempo em que esses dados surgem e são complexos muitos deles divergem. Ao mesmo tempo em que se têm baixos índices sobre políticas de inovação, investe-se pouco no setor. Não há projetos definidos no horizonte de cinco anos, não se promove a aproximação dos institutos de pesquisa e não se conhece as possibilidades de acesso ao dinheiro para a inovação. Mas, metade desta população alega estar preparado para inovação. 


\section{CONSIDERAÇÕES FINAIS}

Após coleta de dados devidamente tabulados, percebeu-se que a região poderia ter mais indústrias nesse porte, pois é um cenário de 1347 indústrias (FIESC, 2015), apenas 14 obedeceu aos quesitos de enquadramento do porte médio. Há ainda um número expressivo de indústrias restantes e excetuando as de grande porte que, também estão em número mínimo, todas as demais estão nos portes de microempresa e empresas de pequeno porte. Acaba sendo inevitável não se perguntar, por que as indústrias da região não crescem em número de colaboradores?

Para que a inovação seja inserida em uma empresa, um dos passos iniciais é o alinhamento da equipe com a cultura organizacional, e isso deve partir da direção. Por isso, entrevistou-se $100 \%$ de diretores e raras foram as vezes que este assunto veio à tona espontaneamente.

Da população entrevistada, a primeira constatação refere-se à disparidade entre ambas em relação a processos, seja de gestão de pessoas ou em máquinas e equipamentos. Enquanto algumas estão com altos investimentos em maquinários e processos de produção, a outra metade sequer tem qualquer investimento na área, mas respondem ser importante um planejamento com verbas definidas não somente para a inovação, mas para capacitações entre outros planejamentos.

Surgiu, com alguma periodicidade, o relato de que algumas empresas realizam algumas atividades chaves para a inovação como capacitação, investimentos, comunicação digital, entre outras, mas as executa muito mais por experiência e bom senso do que seguindo métricas objetivas. Ao julgar pelo sucesso econômico e financeiro dessas empresas aliado a décadas de experiência, evidentemente não se pode alegar que esta tática não funcione. Em alguns casos funciona muito bem, mesmo que sempre paire a dúvida "e se" fosse realizado um trabalho mais organizado com planejamento definido por áreas, qual o impacto real nesses índices? Percebe-se que esse tipo de informação nem sempre está claro o suficiente para o industriário que desfruta de bons números e está contente com esse panorama.

A grande maioria dessas indústrias respondeu que são vistas como referências e fonte de informações junto aos seus pares de atuação e que somando os maiores índices obteve-se um percentual de $78,5 \%$ nesse quesito.

Na pesquisa, "a inovação nas indústrias de médio porte nas indústrias da região da AMAUC: conhecimento x aplicabilidade", destacou alguns pontos para reflexão e possíveis sugestões para outras pesquisas.

Como foi trabalhada uma escala de 01 a 05 para mais e menos atende, levou-se em conta também a segurança da indústria no posicionamento da escala principalmente nos níveis 5 e 4 que configuram uma certeza maior nos seus processos e na corroboração das atividades realizadas.

Um ponto indiscutível repousa sobre a existência de inovação em algumas dessas indústrias. Algumas com maior eficiência e apuro técnico, outras com muita vontade e com alguma desinformação sobre práticas inovadoras.

Quanto às possibilidades de acesso ao dinheiro público e privado para subsidiar a inovação o dado é ainda mais surpreendente, pois somados os dois menores índices 85,7 
desconhecem tais possibilidades, e dos que conhecem preferem não utilizar em razão dos trâmites burocráticos.

Pelo porte e pela importância destas indústrias no cenário regional, estadual, nacional e em alguns casos com negócios fora do país, a inovação poderia ser mais contundente. Existem bons projetos inovadores em algumas delas, mas na grande maioria com pouca sistematização técnica, baixa condição em termos de estrutura própria de P\&D\&। ou mesmo contratada. Mesmo as universidades e institutos não são utilizados como solução e em alguns casos nem vistos como interessantes, outro ponto que caberia nova pesquisa.

Destaca-se que o objetivo da pesquisa foi alcançado. Assim é possível avaliar de maneira mais criteriosa mediante os dados coletados o cenário da inovação e o nível de conhecimento e envolvimento das indústrias de médio porte da região da AMAUC, bem como suas aplicabilidades nessa área.

De acordo com as respostas, as indústrias pesquisadas, na sua grande maioria, não conhecem teórica e sistematicamente as práticas da inovação. No entanto, realizam muitos processos avaliados como inovadores, mas sem apuro técnico evidente. Pode-se dizer que o conhecimento sobre inovação é superficial e a aplicabilidade é proporcional.

Surgiram algumas dificuldades já esperadas, como a demora nos agendamentos, generalizada falta de entendimento conceitual sobre o tema por parte da população, muito embora, conforme outras pesquisas e artigos, esse fator apareça em diversos outros estudos. Pois, tanto em livros como em outras publicações acerca do tema, impera por vezes, uma incongruência nas definições técnicas que abrem espaço para interpretações dissonantes sobre a inovação.

Assim, a indústria nem sempre está interessada em discutir conceitos, mas sim, na obtenção de resultados positivos que para ela sejam significativos e, não necessariamente, ditados por um edital para investimento ou um manual de práticas. Visa assim, uma ação fim, sem levar em conta os meios, justamente onde repousa de fato a engrenagem que leva à inovação.

Pontua-se um dado que não foi levantado, mas pode ser providencial para uma pesquisa no futuro. Trata-se do perfil do empresário frente à inovação, destacando suas competências, conhecimentos, sua abertura ao assunto e sua condição teórico-prática para inovar.

De maneira geral e sob um ponto de vista bastante técnico, pode-se afirmar que o cenário pesquisado não obedece aos principais quesitos exigidos pelas teorias da inovação que são: políticas de capacitação, políticas de investimento a inovação, cultura organizacional voltada à inovação e a tolerância a riscos, acesso e conhecimento a recursos para inovação, vínculos com instituições para desenvolvimento de novas tecnologias, produtos e processos e acompanhamento sistematizado dos projetos em andamento.

Isso não significa afirmar que não há bons lampejos inovadores, mas que normalmente foi sedimentado mais por algum gestor inovador do que por uma cultura à inovação. Pode-se, entretanto, afirmar que o pouco que existe é qualitativamente significante, porém numericamente tímido.

O que fica evidente na região pesquisada diz respeito a um grande potencial inoperante, que oferece boas condições financeiras e de estrutura para que a inovação se desenvolva. Mas, a preocupação em inovar ainda não é genuína e muito menos sistêmica, pois ora se guia somente por resultados, ora somente por coesão financeira. Tem-se a 
impressão que raramente guia-se por algo também primordial na inovação que é fazer melhor, o que ninguém ainda fez, e somente então, gerar um valor real.

\section{REFERÊNCIAS}

ARAÚJO, G.D; SILVA, A.B; BRANDÃO, J.M.F. O que revela a literatura internacional sobre os vínculos em aprendizagem, competências e inovação? Revista de Administração e Inovação - USP, São Paulo, v.12, n.2, p.07-37, abr./jun. 2015. Disponível em: <http://www.revistas.usp.br/rai/article/view/100330> Acesso: em 08 dez. 2015.

BRASIL. Senado.gov.br. Indicadores de inovação tecnológica no mundo: a posição do Brasil nos rankings. Disponível em: < (http://www.senado.gov.br/noticias/Jornal/emdiscussao/inovacao/inovacao-tecnologicano-mundo-brasil.aspx) > Acesso em: 08 dez. 2015.

CESAR.ORG.BR. Manual de incentivos à inovação: Como gerar inovação usando incentivos governamentais no Brasil.., $2009 . \quad$ Disponível em: $<$ www.cesar.org.br/pic/download/processo cesar de inovacao2.pdf. $>$ Acesso: em $08 \mathrm{dez}$. 2015.

CONFEDERAÇÃO NACIONAL DA INDÚSTRIA. Inovar é fazer: 22 casos de empresariais de inovação de micro, pequenas, médias e grandes empresas. Confederação Nacional da Indústria: Serviço Brasileiro de Apoio às Micro e Pequena empresas. Brasília: CNI, 2015.

CROSSAN, M.M; APAYDIN, M. A multi-dimensional framework of organizational innovation: A systematic review of the literature. Journal of the managements studies, London, v.47, n.6, p.1154-1191, September. 2010.

DAVILA, T.; EPSTEIN, M. J.; SHELTON, R. As regras da inovação: como gerenciar, como medir e como lucrar. Porto Alegre: Bookman, 2007.

EMPREGO E HORAS TRABALHADAS CAEM PELO NONO MÊS CONSECUTIVO.

Portaldaindústria.com.br, Brasília, 08 dez. 2015. Disponível em: $<$ http://www.portaldaindustria.com.br/cni/publicacoes-eestatisticas/estatisticas/2015/11/1,38498/indicadores-industriais.html> Acesso: em 08 dez. 2015.

FIESC. Disponível em: < http://fiesc.com.br/.> Acesso em: 09 dez. 2015.

FINEP. Manual de Oslo: Diretrizes para a coleta e interpretação de dados sobre inovação, 3ed. FINEP, 2005. Disponível em: <http://www.finep.gov.br/como-obter-financiamentocomponent?op=empresa > Acesso em: 08 dez. 2015.

FECAM. Disponível em: < http://www.fecam.org.br/municipios/. > Acesso em: 09 dez. 2015. 
FONSECA. M.L. Entrevista concedida a Evandro Carlos Pedroso. Florianópolis, 09 set. 2015.

GALBRAITH, J. R. Projetando a organização inovadora. In: STARKEY, Ken (Ed.). Como as organizações aprendem: relatos do sucesso das grandes empresas. São Paulo: Futura, p. 190-218, 1997.

GRIZENDI, E. Manual sobre orientações gerais sobre inovação. Ministério das Relações exteriores, 2010. Disponível em: <www.softex.br/wp-content/uploads/2013/07/ManualInovação.pd> Acesso em: 08 dez. 2015.

INNOSUPPORT.NET. Disponível em: $<$ http://www.innosupport.net/uploads/media/1._Caracteristicas_e_tipos_de_inovacao_01.p df> Acesso em: 08 dez. 2015.

MALDANER, L.F. O desafio da inovação: Brasil X Coreia do Sul. Novo Hamburgo: Feevale, 2006.

Manual de Oslo. (2005). Diretrizes para coleta e interpretação de dados sobre inovação. (3a ed.). Paris: OCDE - Organização para Cooperação Econômica e Desenvolvimento.

MATTOS, J.R.L; GUIMARÃES, L.S. Gestão da tecnologia e inovação: Uma abordagem prática. São Paulo: Saraiva, 2005.

MARCONI, M.A; LAKATOS, E.M. Fundamentos de metodologia científica. 7ạ ed. São Paulo: Atlas, 2010.

OLIVEIRA, M.F. Metodologia Científica: Um manual para a realização de pesquisas em administração. Catalão, UFG, 2011. Disponível em: <https://adm.catalao.ufg.br/.../Manual_de_metodologia_cientifica_-_Prof_.>Acesso: em 08 dez. 2015.

0 retrato do treinamento no Brasil 2013/2014. Portal.abtd.com.br, São Paulo, 08 dez. $2015 . \quad$ Disponível em: <http://portal.abtd.com.br/Conteudo/Material/Arquivo/PesquisaABTD20132014.pdf) > Acesso em: 08 dez. 2015.

PROENÇA, A. et al. Gestão da inovação e competitividade no Brasil: Da teoria a prática [recurso eletrônico]. Porto Alegre: Bookman, 2015.

PANIZZON, M. et al. Capacidades dinâmicas baseadas em conhecimento e tipos de inovação: Proposição de um framework de análise. Revista de Administração e InovaçãoUSP, São Paulo, v.12, n.1, p.271-302, jan./mar. 2015. Disponível em: <http://www.redalyc.org/pdf/973/97338294013.pdf> acesso: em 08 dez. 2015.

ROCHA, L.C. Criatividade e inovação: Como adaptar-se às mudanças. Rio de Janeiro: LTC Livros Técnicos e Científicos Editora S.A., 2009. 
RODRIGUEZ, A.; DAHLMAN, C.; SALMI, J. Conhecimento e inovação para a competitividade. Brasília: CNI, 2008.

ROGERS, E.; SHOEMAKER, F. F. Communication of innovations: a cross cultural approach. New York: Free Press, 1971.

ROSARIO, J.M. Automação industrial. São Paulo: Baraúna, 2009.

ROTHWELL, R.; GARDINER, P. Invention, Innovation, Relnnovation and The Role Of The User : A Case Study Of British Hovercraft. Technovation, v. 3, p. 167-186, 1985

SCHUMPETER, J. A. Teoria do desenvolvimento econômico: uma investigação sobre lucros, capital, crédito, juro e o ciclo econômico (1 ed., 1934). Tradução de Maria Sílvia Possas. Coleção Os Economistas. São Paulo: Nova Cultural, 1997.

SERAFIM, L. O poder da inovação: Como alavancar a inovação na sua empresa. São Paulo: Saraiva, 2011.

SC-E-TERCEIRO-ESTADO-NO-RANKING-DE-COMPETITIVIDADE-ENTRE-ESTADOS.HTML. g1. globo.com, São Paulo, 08 dez. 2015. Disponível em: <http://g1.globo.com/sc/santacatarina/noticia/2015/11/sc-e-terceiro-estado-no-ranking-de-competitividade-entreestados.html> Acesso em: 08 dez. 2015.

STORTI, A.T. et al. Trabalhos acadêmicos: da concepção à apresentação. Erechim: EdiFAPES, 2013.

TADEU, H.F.B. Panorama da inovação no Brasil. FDC Executive, Nova Lima, FE1405, Fundação Dom Cabral, 2014.2 Disponível em: <http://www.fdc.org.br/professoresepesquisa/publicacoes/Paginas/publicacaodetalhe.aspx?publicacao=18458> Acesso em: 08 dez. 2015.

Van de Ven, A H et al. Research on the management of innovation Ballinger, Cambridge, MA (1989)

VENDAS-DA-INDÚSTRIA-DE-SC-FECHAM-SEMESTRE-COM-QUEDA. Fiesc.com.br, Florianópolis, 08 dez. 2015. Disponível em: <http://fiesc.com.br/noticias/vendas-daindustria-de-sc-fecham-semestre-com-queda>. Acesso em: 08 dez. 2015.

WOOD JR, T e CALDAS, M.P. Empresas brasileiras e o desafio da competitividade. RAE-FGV EAESP. São Paulo, v.47, n.3, p.66-78, jul./set. 2007. Disponível em: <http://rae.fgv.br/rae/vol47-num3-2007/empresas-brasileiras-desafio-competitividade> Acesso em: 08 dez. 2015. 